\title{
GENDER DIFFERENCES AMONG MOG PLAYERS IN THEIR SOCIALISATION PROCESSES
}

\author{
Ricardo Casañ Pitarch \\ Universitat Politècnica de València \\ ricapi@upv.es
}

\begin{abstract}
The increasing popularity of multiplayer online video games has given rise to the creation of linguistic communities with specific forms of communication and rules. Among the several features of those digital communities, some differences among men's and women's communication behaviours seem to be real when they play video games. Thus, the objective of this research is to analyse gender differences in the socialisation process among MOG Players (Multiplayer Online Game). To this aim, this research introduces an experiment with 201 MOG players (males: 147; females: 54) who responded to a survey concerning the use of 20 social communicative acts (based on Guntermann and June, 1982, p. 26) in three different contexts: the participant knew in advance the other player from a) the real world, b) the virtual world, or c) they had never met before. The results obtained from this analysis have shown some differences between both male and female MOG participants in their socialisation process when interacting with other players by determining the frequency and the per cent variation on the use of the selected communicative acts. In conclusion, it seems that there are some similarities and differences between men and women when interacting with MOG players that may interfere in the way they play videogames and behave towards other players.
\end{abstract}

Keywords: socialising; gender; MOG, videogames; discourse analysis.

\section{Introduction}

The aim of this paper is to analyse gender differences and similarities when MOG Players (Multiplayer Online Game) attempt to socialise with other players within the same virtual world. More concretely, the objective of this research is to identify and justify the use of 20 social communicative acts, which were initially proposed by Guntermann and June (1982, p. 26) in their taxonomy and we have slightly redefined. Besides, these communicative acts have been analysed from three different perspectives: when players knew each other from the real world, players who knew each other from the virtual world and players that were mutually unknown. As result, this paper shows the frequency and relevance of the selected social communicative acts among both male and female players in MOG. Based on previous research, it is assumed that there are some Gender differences between men and women that affect the way they interact with other players within this video game genre (Olson, Kutner \& Warner, 2008; Paraskeva, Mysirlaki, \& Papagianni, 2010; Yee, 2006).

Studies on video games and discourse analysis have proliferated in the present decade in the field of linguistics as a result of the noticeable advances in technology during this same period that currently have permitted that video game users can play online with other players worldwide (Ensslin, 2011, 2015; Gee, 2015; Paul, 2012; Perez Latorre, 2015; Stamenković, Jaćević \& Wildfeuer, 2017). In the present, most homes have powerful computers and fast internet service; this has also coincided with the rising sales of MOG, resulting in one of the most profitable industries. Siwek $(2017$, p. 5) explained that the sales of video games in the US generated over $\$ 23.5$ billion in 2015, whereas Nieborg and de Kloet (2016, p. 207 ) suggested that the worldwide industry reached $\$ 99.6$ billion in 2016. These results seem to be clear evidence that the community of gamers is fastly growing, and with them the creation of online gaming communities with their own discursive, linguistic and behaviour rules. Therefore, these brand new communities seem to be worth studying; and this paper attempts to fulfil this research purpose by responding to two research questions that have been formulated below:

RQ1) which are the most usual social communicative acts among male and female players?

RQ2) is there any variation on the use of social communicative acts when men and women interact with people they know from the real and virtual worlds and with unknown people?

\section{Theoretical Framework}

Gender Differences in Communication and Social Communicative acts

In speech communities, there are different variations that may affect age, social or economic status, origin or gender among many others. Speech variation between men and women is a sociolinguistic issue that affects any different use of the language in each gender. Lakoff (1973, p. 45) established that the connection between language and gender as a part of the linguistics in which social factors, obligations, constraints and freedom cannot be separated from discourse. In this line, studies on language and gender aim to explain why man and women behave in the same way or differently in any specific social environment. These speech variations tend to be rooted in both cultural and historical reasons and they tend to differ from one to other communities. 
It shall be noticed that history and culture are factors that individuals are not born with, but they are acquired as they grow. Thus, it would be erroneous to consider that gender differences are only influenced by a genetic base. Eckert and McConnell-Ginet (2003, p. 10) stated that young children tend to follow the habits of the people that they admire such as their parents, older siblings, grandparents, uncles and aunts, or siblings, among others. In most communities, when children are imitating them, it seems that it is part of the nature of most adults to correct the young kids if they do an action which is associated with the opposite gender, for example, a boy using high heels or a young girl acting as she is shaving her beard. This does not necessarily imply violence or reprimand, it can simply be a naive comment or some unconscious advice indicating that a particular action is associated with the opposite gender. Consequently, kids quickly understand that they belong to a social group naturally determined by gender and there are some conditions and rules that must be respected because it is what the people that they admire do.

In this line, there are several decisions and actions that people from a particular community do either consciously or unconsciously that imply the creation and perseverance of a conceptual system which actually distinguishes male and female roles. The norms associated with these roles are consequently naturalised by the members of any particular community and they rarely tend to feel gifted or offended. Moreover, these distinguishing tags can even become institutionalised and part of the education system. The influence of conscious and unconscious factors like the previous ones should definitely help understand why there are social differences associated with gender and language. As result, some previous studies have noticed some communication differences between men and women. For example, Tannen (1995, p. 111) formerly suggested that men tend to communicate with the aim of presenting factual information and more oriented towards a problem-solving approach, whereas women are more likely to communicate to build and maintain relationships and tend to follow a process-oriented approach. In addition, Pease and Pease (2000, p. 68) introduced their opinion on some facts in which men and women were completely opposite. Among other facts, their book suggests that there are cognitive differences; for example, they explain that men tend to have better spatial, logical and perceptual skills than women and they also excel at mathematics, building, and puzzles by nature. On the contrary, most women tend to manage their emotional intelligence better than men, and they also have "a greater range of sensory equipment and, with that multiplicity of fibre connections for faster transfer of information between the hemispheres, women can make so many fast, accurate judgements about people and situations on an intuitive level" (Pease and Pease, 2000, p. 69). In this sense, it seems to these authors that the more connections the brain has, the more fluent the individual is; thus, women seem to be in advantage in this field. At last, and among other ideas, these authors also suggest that men are more direct at communicating and women more indirect.

Considering that some authors have experimented and defined some ideas and facts which establish some differences between male and female individuals in the use of socialising acts, this research should identify and determine the social communicative acts. To this purpose, the taxonomy introduced by Guntermann and June (1982, p. 26) includes a series of communicative acts that could be used as a possible model to implement our analysis on the differences between men and women on the socialisation process in MOG. Their list included the following items:

- Greeting others;

- Taking leave;

- Planning to meet again;

- Introducing and meeting people;

- Making small talk;

- Getting to know others;

- Issuing invitations;

- Paying visits and receiving visitors;

- Offering things;

- Sharing leisure activities;

- Joking;

- Flirting;

- Telling or listening to stories, recounting events;

- Gossiping;

- Expressing feelings;

- Apologising and reacting to apologies;

- Displaying accomplishments. 


\section{An Introduction to Multiplayer Online Games}

The current increase of interest in the world of video games has led to new perspectives on academic research within this field. This notorious rise in their use is probably linked to the digital revolution in the 2010s, which was based on the introduction and quickly spread of Smartphones with a faster Internet connection and their easy adaptability to install multiple applications accessible from any device and free or near-free access. In addition, according to the website 'Internet World Stats' (2017), the current population with Internet access is $51.70 \%$, with a global growth of $976.40 \%$ in the period $2000-2017$. In the cases of America and Europe, the present percentages of Internet users are $88.10 \%$ and $80.20 \%$ respectively; this fact means that near all the population in these two continents are 'online'.

This improved Internet connectivity and the increase in the number of users worldwide have made the video game industry evolve towards new series of multiplayer online products. This profitable demand for online video games has given rise to further design and promotion of the genre of multiplayer online games (MOG) (Childress \& Braswell, 2006, p. 188). Among other definitions provided by different authors, Steinkuehler (2006, p. 887) stated that MOG are:

"highly graphical 2- or 3-D video games played online, allowing individuals, through their self-created digital characters or 'avatars', to interact not only with the gaming software but with other players' avatars as well. These virtual worlds are persistent social and material worlds, loosely structured by open-ended (fantasy) narratives, where players are largely free to do as they please".

MOG could be considered the hypernym of a series of sub-genres or hyponyms in the video game industry. In this sense, MOG can derive to role-playing (MMORPG, i.e.: World of Warcraft), first person shooter (MMOFPS, i.e.: Counter Strike), real time strategy (MMORTS, i.e.: Age of Empires), sports (MMOSG, i.e.: FIFA'18), racing (MMOR, i.e.: Need for Speed: World), dance (MMOD, i.e.: Dance Dance Revolution), or battle arena (MOBA, i.e.: League of Legends) among others, as well as to others that have not been tagged yet such as simulations (The Sims), social (Second Life), and causal or miscellaneous (puzzles, trivial, card games).

As previously cited, one of the main features of these video games is that they allow interaction among users. In this sense, gamers communicate with other users with the aim of fulfilling specific purposes connected to the virtual and they create their own communities. These exchanges require the use of particular language functions as it occurs in any other discipline, whereas the communities create certain linguistic norms. As a result, these new online scenarios with their own virtual communities or tribes are part of our present daily lives and they have led to the creation and development of online gaming communities, being a relatively new concept that is characterised by both traditional and real-world features as well as components related to virtual worlds.

\section{Gender differences at playing Video games}

Yee (2006), stated that "different people choose to play games for very different reasons, and thus, the same video game may have very different meanings or consequences for different players" (p. 774). It is unquestionable that when thinking of differences at playing video games, there are near infinite variables that could be considered such as age, experience, personality, or gender among many others. For the aim of this research, gender is the main focus of attention, among all the possible variables.

To start with, society has tagged video games as a men's game or it has been considered that men have been more attracted by video games than women (Hartmann \& Klimmt, 2006; Ivory, 2006; Fox \& Tang, 2014; Winn \& Heeter, 2009). More recently, other studies suggest that this situation is currently changing and there is an increasing amount of female gamers (Cunningham, 2016; Dale \& Green, 2017; Harwell, 2014; Williams, Martins, Consalvo, \& Ivory, 2009). Paraskeva, Mysirlaki and Papagianni, (2010, p. 504) justified that this possible difference in video game use could be related to the fact that the nature of commercial games is not well balanced and they do not focus on the interest of female adolescents as much as they do with males (e.g.: most principal videogames characters are male). However, this issue seems to be irrelevant in this research since our aim is to analyse gender differences at socialising rather than considering the percentage of women and men who play video games nowadays.

To describe the differences among men and women playing MOG, Olson, Kutner and Warner (2008, p. 63) listed some differences in gaming based on her own research. In this sense, it seems that men use video games to experiment power and glory, to get excited in realistic environments and to release their feelings of anger and stress; in addition, they also tend to use video games to socialise with other players through competition and cooperation. On the contrary, female gamers also use video games to express their feelings and socialise but it seems that they attempt "to build supportive social networks, escape from real life stress and to be immersed in a fantasy world" (Paraskeva, Mysirlaki, \& Papagianni, 2010, p.500). 
According to this previous comparative, it seems that both genders use video games to socialise regardless of the number of players in each group. The difference could be in the way they socialise or in the type of communicative acts that they use and its frequency. In connection to this idea and relevant to our research were the words of Yee (2006, p. 324), who affirmed that there is some difference among genders in their motivation to play but not in the socialisation process despite there is a connection between them. Thus, it seems that men and women equally socialise but they aim at finding different things. Consequently, this fact implies that an analysis of the use of social strategies among a group of men and another one of women could respond to our experimental questions previously formulated in the introduction. With an analysis of gender differences at socialising in MOG video games, it is expected to identify the most common social communicative acts for both male and female players, their frequency, and differences on their use with different familiar or unknown people.

\section{Method}

As previously mentioned, this experiment has been based on the responses of 201 MOG players. These participants completed an online questionnaire that was circulated through gaming forums and among university students between September and December 2017. Among these participants, 147 were male $(n=$ $73.13 \%)$ and 54 female $(n=26.87 \%)$. These participants confirmed to be MOG players and consequently were considered for the present experiment. The survey consisted of anonymous questions divided into two blocks. On the one hand, respondents were enquired on a series of questions about their demographic profile; and on the other hand, they also had to respond to some questions concerning the players' individual use of twenty social communicative acts adapted from the list formerly introduced by Guntermann and June (1982), and they were also set in three different contexts: the participant knew in advance the other player from a) the real world, b) the virtual world, or c) they had never met before.

The procedure to analyse the results obtained focused on the frequency of each communicative act in the three possible contexts by both male and female participants. Then, results were compared and the per cent variation was calculated in order to determine their relevance within this study. To complete this research the software SPSS was used to calculate percentages and per cent variation among the different items analysed.

\section{Results}

The present research has compiled some results that are shown in the following lines and tables. In this sense, these results have focused on the interactions among MOG Male and Female players with other players from different contexts as well as on the frequency of use of some social communicative acts among male and female participants.

To start with, table 1 shows the frequency in which male and female players interact with other MOG users. In this case, a variable of proximity with other players has been introduced and it has distinguished among players that they know from the real world, players that they know from the virtual world and players that they do not know. By comparing the first two columns, it can be observed that male participants affirmed that they tend to overall interact more often with other participants than female participants $(6.42 \%)$. These results also show that both groups communicate more often with players they know from the real world than with players they know from the virtual world or with unknown ones. However, if the per cent variations from the three contexts are compared, results show that the difference between male and female participants is more significant in terms of interactions with these three groups. As it can be observed, the per cent variation between men and women when they interact with people that they know from the real world is $4.18 \%$, with people they know from the virtual world is $7.43 \%$, and this variation is $8.36 \%$ if the participants do not know the other players. Thus, it seems that the more distant is the other player, the less they will interact; and this fact is more remarkable among female participants.

Interactions with other MOG players

Table 1

\begin{tabular}{|c|l|c|c|c|}
\hline$\#$ & \multicolumn{1}{|c|}{ Context } & Male & Female & \% Variation \\
\hline 1 & You know the other player from the real world & 3.52 & 3.38 & $4.18 \%$ \\
\hline 2 & You know the other player from the Virtual world & 3.07 & 2.86 & $7.43 \%$ \\
\hline 3 & You don't know the other player & 2.61 & 2.41 & $8.36 \%$ \\
\hline- & General Interaction & 3.07 & 2.88 & $6.42 \%$ \\
\hline
\end{tabular}

Secondly, considering the frequency of the social communicative acts among male and female participants, results have shown that in most cases men affirmed that they use these social acts more often than women. Besides, both groups seem to use these social acts more often with players they know from the 
real world than with players they know from the virtual world and less often with players they do not know. Furthermore, results in table 2 also show that the differences among men and women tend to increase as the other players are more distant. In this sense, some of the results obtained from the social acts analysed should be explained individually. For example, women are more constant at saying goodbye once their conversation has started; according to these results women say goodbye slightly more often to other players they do not know in comparison to men despite men tend to use this act more often when it comes to people they know from the real world. Concerning the use of small talks and flirting, female participants affirmed that they use these social acts more often than men when they deal with people they know; on the contrary, men are more likely to use these acts with unknown players. In reference to other acts that women used more often than men, results have shown that they apologise and compliment more often with people they know from the real world. On the contrary, results have shown that men greet, introduce others, and interrupt politely unknown player considerably more often than women do. Similarly, male participants seemed to interact with players they known from either real or the virtual worlds to make plans to meet again in the virtual world or invite others to actions more often than women. In the same way, men tend to joke in MOG more women within the three possible contexts. At last, if these social acts are ranked comparing their use among men and women, it seems that men use the following acts more often: saying goodbye, thanking, congratulating, joking, and sympathising. On the contrary, women preferred the following ones: thanking, saying goodbye, sympathising, showing understanding, and congratulating. In this sense, it seems that the order only changes a bit and there are no significant changes.

Table 2

Frequency of communicative acts among male and female participants

\begin{tabular}{|c|c|c|c|c|c|c|c|}
\hline Communicative Act & Male & Fem. & $\%$ Variat. & Communicative Act & Male & Fem. & $\%$ Variat. \\
\hline Greeting [RW] & 3.98 & 3.89 & $2.31 \%$ & Plans to meet in the RW [RW] & 3.27 & 3.04 & $7.57 \%$ \\
\hline Greeting [VW] & 3.45 & 3.24 & $6.48 \%$ & Plans to meet in the RW [VW] & 2.33 & 2.09 & $11.48 \%$ \\
\hline Greeting [UNK] & 2.71 & 2.30 & $17.83 \%$ & Plans to meet in the RW [UNK] & 1.50 & 1.43 & $4.90 \%$ \\
\hline Mean: Greeting & 3.38 & 3.14 & $8.87 \%$ & Mean: Plans Meeting RW & 2.37 & 2.19 & $\mathbf{7 . 9 8 \%}$ \\
\hline Introducing yourself [RW] & 3.61 & 3.57 & $1.12 \%$ & Complimenting [RW] & 3.59 & 3.63 & $-1.10 \%$ \\
\hline Introducing yourself [VW] & 3.20 & 3.07 & $4.23 \%$ & Complimenting [VW] & 3.24 & 3.06 & $5.88 \%$ \\
\hline Introducing yourself [UNK] & 2.54 & 2.41 & $5.39 \%$ & Complimenting [UNK] & 2.84 & 2.59 & $9.65 \%$ \\
\hline Mean: Introducing yourself & 3.12 & 3.02 & $3.58 \%$ & Mean: Complimenting & 3.22 & 3.09 & $4.81 \%$ \\
\hline Introducing others [RW] & 3.35 & 3.17 & $5.68 \%$ & Praising [RW] & 3.40 & 3.33 & $2.10 \%$ \\
\hline Introducing others [VW] & 2.99 & 2.65 & $12.83 \%$ & Praising [VW] & 3.06 & 2.80 & $9.29 \%$ \\
\hline Introducing others [UNK] & 2.50 & 2.09 & $19.62 \%$ & Praising [UNK] & 2.69 & 2.41 & $11.62 \%$ \\
\hline Mean: Introduce others & 2.95 & 2.64 & $12.71 \%$ & Mean: Praising & 3.05 & 2.85 & $7.67 \%$ \\
\hline Good bye $[\mathrm{RW}]$ & 4.36 & 4.17 & $4.56 \%$ & Congratulating [RW] & 4.02 & 3.87 & $3.88 \%$ \\
\hline Good bye [VW] & 4.08 & 3.85 & $5.97 \%$ & Congratulating [VW] & 3.67 & 3.39 & $8.26 \%$ \\
\hline Good bye [UNK] & 3.52 & 3.54 & $-0.56 \%$ & Congratulating [UNK] & 3.38 & 3.02 & $11.92 \%$ \\
\hline Mean: Good Bye & 3.99 & 3.85 & $3.32 \%$ & Mean: Congratulate & 3.69 & 3.43 & $8.02 \%$ \\
\hline Plan to meet again in VW [RW] & 3.84 & 3.28 & $17.07 \%$ & Apologising [RW] & 3.75 & 3.78 & $-0.79 \%$ \\
\hline Plan to meet again in VW [VW] & 2.87 & 2.43 & $18.11 \%$ & Apologising [VW] & 3.49 & 3.19 & $9.40 \%$ \\
\hline Plan to meet again in VW [UNK] & 1.99 & 1.81 & $9.94 \%$ & Apologising [UNK] & 3.25 & 2.94 & $10.54 \%$ \\
\hline Plans to Meet again VW & 2.90 & 2.51 & $15.04 \%$ & Mean: Apologising & 3.50 & 3.30 & $6.38 \%$ \\
\hline Small Talks [RW] & 2.88 & 3.00 & $-4.00 \%$ & Sympathising [RW] & 4.01 & 3.93 & $2.04 \%$ \\
\hline Small Talks [VW] & 2.56 & 2.61 & $-1.92 \%$ & Sympathising [VW] & 3.50 & 3.39 & $3.24 \%$ \\
\hline Small Talks [UNK] & 2.23 & 2.07 & $7.73 \%$ & Sympathising [UNK] & 3.07 & 3.04 & $0.99 \%$ \\
\hline Mean: Small Talk & 2.56 & 2.56 & $0.60 \%$ & Mean: Sympathising & 3.53 & 3.45 & $2.09 \%$ \\
\hline Inviting others to action[RW] & 3.62 & 3.02 & $19.87 \%$ & Thanking [RW] & 4.24 & 4.17 & $1.68 \%$ \\
\hline Inviting others to action[VW] & 2.71 & 2.33 & $16.31 \%$ & Thanking [VW] & 3.90 & 3.87 & $0.72 \%$ \\
\hline Inviting others to action[UNK] & 1.97 & 1.76 & $11.93 \%$ & Thanking [UNK] & 3.70 & 3.61 & $2.51 \%$ \\
\hline Mean: Inviting & 2.77 & 2.37 & $16.04 \%$ & Mean: Thanking & 3.95 & 3.88 & $1.64 \%$ \\
\hline Joking $[\mathrm{RW}]$ & 4.23 & 3.74 & $13.10 \%$ & Showing Understanding [RW] & 3.92 & 3.85 & $1.78 \%$ \\
\hline Joking [VW] & 3.77 & 3.24 & $16.36 \%$ & Showing Understanding [VW] & 3.52 & 3.46 & $1.84 \%$ \\
\hline Joking [UNK] & 3.03 & 2.65 & $14.34 \%$ & Showing Understanding [UNK] & 3.14 & 3.02 & $4.07 \%$ \\
\hline Mean: Joking & 3.68 & 3.21 & $14.60 \%$ & Mean: Show. Understanding & 3.53 & 3.44 & $2.56 \%$ \\
\hline Flirting [RW] & 1.76 & 1.87 & $-5.88 \%$ & Interrupting Politely [RW] & 3.04 & 2.91 & $4.50 \%$ \\
\hline Flirting [VW] & 1.56 & 1.56 & $0.00 \%$ & Interrupting Politely [VW] & 2.74 & 2.48 & $10.54 \%$ \\
\hline Flirting [UNK] & 1.59 & 1.43 & $11.19 \%$ & Interrupting Politely [UNK] & 2.63 & 2.2 & $19.67 \%$ \\
\hline Mean: Flirting & 1.64 & 1.62 & $1.77 \%$ & Mean: Interrupting Politely & 2.80 & 2.53 & $11.57 \%$ \\
\hline Gossiping [RW] & 2.52 & 2.50 & $0.80 \%$ & Time to Consider[RW] & 3.05 & 2.89 & $5.45 \%$ \\
\hline Gossiping [VW] & 2.05 & 1.85 & $10.81 \%$ & Time to Consider[VW] & 2.77 & 2.65 & $4.48 \%$ \\
\hline Gossiping [UNK] & 1.57 & 1.56 & $0.64 \%$ & Time to Consider[UNK] & 2.35 & 2.3 & $2.34 \%$ \\
\hline Mean: Gossiping & 2.05 & 1.97 & $4.08 \%$ & Mean: Time to Consider & 2.72 & 2.61 & $4.09 \%$ \\
\hline
\end{tabular}




\section{Discussion and Conclusion}

This research has aimed at analysing some differences among male and female MOG players when socialising with other players. To this purpose, two research questions were formulated in order to discuss the main gender differences among MOG players during their socialisation process with other players. The results obtained and the theoretical framework that have previously been introduced in this paper are the basis to discuss these questions.

To start with, it has been noticed that the participation in this research was predominated by men; and according to our results, men seemed to use the proposed social communicative acts more often than women. As it has been commented in the results section, the level of interaction of men in MOG was 3.07, whereas it was 2.88 among women. Connected to this fact, the first research question suggested that there could be some social acts that male and female participants used more often than the opposite gender. However, it has been found that the ranking of the communicative acts most frequently used by men and women did not vary significantly from one gender to the other from an overall perspective; as it had been suggested by Yee (2006, p. 324). However, it shall be acknowledged that there are some relevant variations within some individual communicative acts regarding their frequency and order in the ranking as it could be observed in the results section. In this sense, it shall be acknowledged that the per cent variation among genres could be up to near $20 \%$ in some cases, despite the mean variation between men and women was rather inferior, $6.42 \%$.

In reference to the second research question on possible variations concerning the use of social communicative acts when men and women interact with other people, results have shown that both male and female participants were more reluctant to talk with unknown players than with players they know from either the virtual or the real worlds. Besides, in most cases, our participants also affirmed that they tend to interact the most with players they know from the real world rather than with players they know from the virtual one. Thus, it seems that the variable of proximity influences in the degree of socialisation among MOG players when it comes to using social communicative acts. Furthermore, the difference between male and female on the use of social acts differs if this variable is considered. In this sense, female participants were considerably more reluctant to socialise with other unknown players or with the ones that they know from the real world in comparison to men. In the case of the use of these social communicative acts with players they knew from the real world, the difference was less noticeable despite men were also more likely to socialise with this group of players.

In conclusion, the findings obtained in this research should be considered to justify the attitude and behaviour of male and female MOG players. As commented, it seems that there are some similarities and differences among male and female MOG players. On the one hand, both men are women prefer socialising with people they know from the real world; this could be explained as a matter of confidence or familiarity with other players, and this fact suggests that some relationships in virtual worlds seem to be connected to the real world. On the other hand, men were different to women in terms that males seemed to socialise with other MOG players more often than females. The variable of proximity affected to both genres, but the correlation was more significant among women. At last, some social communicative acts seemed to be more usual within one gender than within the other.

In further research, new variables could be considered and combined with gender such as age, experience with video games, or personality among others. In addition, it would also be necessary to extend the number of participants in order to make a balance among the participants of both groups, especially women. At last, the main difficulty in this study has been to find suitable participants who were MOG players. It seems that men are more likely to play this type of video games or at least they were more willing to fill out our survey; consequently, the gender balance has clearly been destabilised.

\section{References:}

Childress, M. D., \& Braswell, R. (2006). Using massively multiplayer online role-playing games for online learning. Distance Education, 27 (2), 187-196. https://doi.org/10.1080/01587910600789522.

Cunningham, C.M. (2016). She designs therefore she is? Evolving understandings of video game design. In K.D. Valentin and L.J Jensen (Eds.), Examining the Evolution of Gaming and Its Impact on Social, Cultural, and Political Perspectives (pp. 147-169). Hershey, PA: IGI Global. https://doi.org/10.4018/978-1-5225-0261-6.ch007.

Dale, G., \& Green, C. S. (2017). The Changing Face of Video Games and Video Gamers: Future Directions in the Scientific Study of Video Game Play and Cognitive Performance. Journal of Cognitive Enhancement, 1 (3), $280-294$. https://doi.org/10.1007/s41465-017-0015-6.

Eckert, P., \& McConnell-Ginet, S. (2003). Language and gender. New York, NY: Cambridge University Press. https://doi.org/10.1017/CBO9780511791147.

Ensslin, A. (2011). The language of gaming. London: Palgrave Macmillan.

Ensslin, A. (2015). Discourse of games. In Cornelia Ilie \& Karen Tracy (eds.), The International Encyclopedia of Language and Social Interaction (pp. 1-6). Hoboken, NJ: Wiley Online. https://doi.org/10.1002/9781118611463.wbielsi154 
Fox, J., \& Tang, W. Y. (2014). Sexism in online video games: The role of conformity to masculine norms and social dominance orientation. Computers in Human Behavior, 33 (1), 314-320. https://doi.org/10.1016/j.chb.2013.07.014

Gee, J.P. (2015). Discourse analysis of games. In R. H. Jones, A. Chik, \& C.A. Hafner (Eds.), Discourse and digital practices: doing discourse analysis in the digital age (pp. 18-27). New York, NY: Routledge.

Guntermann, G. and June K.P. (1982). Functional-Notional Concepts: adapting the FL textbook. Washington, D.C: Center for Applied Linguistics. ISBN: 0-87281-301-0.

Harwell, D. (2014). More women play video games than boys, and other surprising facts lost in the mess of Gamergate. Washington Post. Retrieved on May 5, 2018 from: https://www.washingtonpost.com/news/the-switch/wp/2014/10/17/more-womenplay-video-games-than-boys-and-other-surprising-facts-lost-in-the-mess-of-gamergate/?utm_term=.0d229fc03907

Hartmann, T., \& Klimmt, C. (2006). Gender and computer games: Exploring females' dislikes. Journal of Computer-Mediated Communication, 11 (4), 910-931. https://doi.org/10.1111/j.1083-6101.2006.00301.x.

Internet World Stats (2017). Usage and population statistics. Retrieved on May14, 2018 from http://www.internetworldstats.com/stats.htm

Ivory, J. D. (2006). Still a man's game: Gender representation in online reviews of video games. Mass Communication \& Society, 9 (1), 103-114. https://doi.org/10.1207/s15327825mcs0901_6

Lakoff, R. (1973). Language and Woman's Place. New York, NY: Harper \& Row. https://doi.org/10.1017/S0047404500000051.

Olson, C., Kutner, L., \& Warner, D. (2008). The Role of Violent Video Game Content in Adolescent Development. Journal of Adolescent Research, 23 (1), 55-75. https://doi.org/10.1177/0743558407310713.

Nieborg, D.B., de Kloet J. (2016). A Patchwork of Potential: A Survey of the European Game Industry. In A. Fung (ed.), Global Game Industries and Cultural Policy, pp. 201-226. Palgrave Macmillam: London. https://doi.org/10.1007/978-3-31940760-9_10

Paraskeva, F., Mysirlaki, S., \& Papagianni, A. (2010). Multiplayer online games as educational tools: Facing new challenges in learning. Computers \& Education, 54 (2), 498-505. https://doi.org/10.1016/j.compedu.2009.09.001.

Paul, C. A. (2012). Wordplay and the discourse of video games: Analyzing words, design, and play. New York, NY: Routledge. https://doi.org/10.4324/9780203124031.

Pérez Latorre, O. (2015). The social discourse of video games analysis model and case study: GTA IV. Games and Culture, 10 (5), 415-437. https://doi.org/10.1177/1555412014565639.

Pease, A., \& Pease, B. (2016). Why Men Don't Listen \& Women Can't Read Maps: How to spot the differences in the way men \& women think. London: Hachette UK. ISBN: 9780767907637.

Siwek, S. (2017). Video Game in the 21st Century: The 2017 Report. Washington, DC: Entertainment Software Association. Retrieved on May 5, 2018 from http://www.theesa.com/wp-content/uploads/2017/02/ESA_EconomicImpactReport_Design_V3.pdf.

Stamenković, D., Jaćević, M., \& Wildfeuer, J. (2017). The persuasive aims of Metal Gear Solid: A discourse theoretical approach to the study of argumentation in video games. Discourse, Context \& Media, 15 (1), 11-23. https://doi.org/10.1016/j.dcm.2016.12.002.

Steinkuehler, C. A., \& Williams, D. (2006). Where everybody knows your (screen) name: Online games as "third places". Journal of computer-mediated communication, 11 (4), 885-909. https://doi.org/10.1111/j.1083-6101.2006.00300.x

Tannen, D. (2013).You Just Don’t Understand: Women \& Men in Conversation. New York: Harper Collins.

Williams, D., Martins, N., Consalvo, M., \& Ivory, J. D. (2009). The virtual census: Representations of gender, race and age in video games. New Media \& Society, 11 (5), 815-834. https://doi.org/10.1177/1461444809105354.

Winn, J., \& Heeter, C. (2009). Gaming, gender, and time: Who makes time to play? Sex roles, 61 (1), 1-13. https://doi.org/10.1007/s11199-009-9595-7.

Yee, N. (2006). The demographics, motivations and derived experiences of users of massively-multiuser online graphical environments. PRESENCE: Teleoperators and Virtual Environments, 15 (1), 309-329. https://doi.org/10.1162/pres.15.3.309

Received: May 16, 2018

Accepted: May 30, 2018 